\title{
H-RYK, an Unusual Receptor Kinase: Isolation and Analysis of Expression in Ovarian Cancer
}

\author{
Xiao C. Wang,* Roy Katso,* Robin Butler,* \\ Andrew M. Hanby, ${ }^{\dagger}$ Richard Poulsom, ${ }^{\dagger}$ Tania Jones, $^{\neq}$ \\ Denise Sheer, ${ }^{\neq}$and Trivadi S. Ganesan* \\ *ICRF Molecular Oncology Laboratories, Institute of Molecular \\ Medicine, John Radcliffe Hospital, Headington, Oxford, United \\ Kingdom \\ ${ }^{\dagger}$ RCS/ICRF Histopathology Unit and ICRF In Situ Hybridization \\ Service, London, United Kingdom \\ ${ }^{\ddagger}$ Laboratory of Human Cytogenetics, London, United Kingdom
}

\begin{abstract}
Background: Protein tyrosine kinases play an important role in cellular metabolism as key components of signal transduction pathways. They are involved in cellular growth, differentiation, and development. Receptor tyrosine kinases (EGF receptor and c-erbB2) have been shown to be important in the pathogenesis of cancer. In ovarian cancer, overexpression of c-erbB2, a type I receptor, has been correlated with an adverse effect on survival of patients.

Material and Methods: An unusual receptor tyrosine kinase, H-RYK, has been isolated from a complimentary DNA library of SKOV-3, an epithelial ovarian cancer cell line, using a polymerase chain reaction-mediated approach.

Results: The primary structure of the predicted amino acid sequence of the protein shows a novel $\mathrm{NH}_{2}$-terminal region. The catalytic region shows homology to other tyrosine kinases, the closest homology being with $v$-sea $(39 \%)$. A significant alteration in the catalytic domain is that the highly conserved "DFG" triplet in subdomain VII is altered to "DNA." The gene was mapped to chro-
\end{abstract}

mosome 3q22. A single transcript of $3.0 \mathrm{~kb}$ is expressed in heart, brain, lung, placenta, liver, muscle, kidney, and pancreas by Northern analysis with maximal expression in skeletal muscle. In situ hybridization analysis on human tissues demonstrated localization of message in the epithelial and stromal compartment of tissues such as brain, lung, colon, kidney, and breast. There was minimal to absent expression of H-RYK on surface epithelium of ovaries. In benign (3) and borderline tumors of the ovary (5), there was expression in the stromal compartment. However, in malignant tumors (24) there was increased expression predominantly confined to the epithelium. Polyclonal antisera raised against synthetic peptides recognize a $100-\mathrm{kD}$ protein in ovarian cancer cells and other cell lines. In contrast to other receptor tyrosine kinases, the receptor did not phosphorylate in an in vitro kinase assay.

Conclusions: The expression of this unusual receptor tyrosine kinase in epithelial ovarian cancer suggests that it may be involved in tumor progression, which needs further investigation.

\section{INTRODUCTION}

Protein tyrosine kinases (PTK) represent a large family of enzymes that share a common highly conserved catalytic domain responsible for signal

Address correspondence and reprint requests to: Trivadi S. Ganesan, ICRF Molecular Oncology Laboratories, Institute of Molecular Medicine, John Radcliffe Hospital, Headington, Oxford, OX3 9DU, United Kingdom. transduction by phosphorylation of substrates on tyrosine residues $(1,2)$. Receptor tyrosine kinases (RTK) are transmembrane proteins that relay the signals from the exterior of the cell, upon stimulation by cognate ligands. These signals are instructions to the cell for various fundamentally important processes such as division and differentiation. The extracellular domain determines 
the specificity of the ligand they bind to, which can be used to subdivide them into different families (3). The downstream signaling pathways have been defined to occur through association with src homology $2\left(\mathrm{SH}_{2}\right)$ domain containing proteins, via ras and the MAP kinases, and also through the STAT kinase pathway, to ultimately stimulate transcription (4-7). Deregulation in any component of this pathway at the level of receptor or downstream elements has been shown to be important in malignant transformation (8). At the level of receptors for example, overexpression of RTKs of the type I class, like EGF and c-erbB2, have been implicated in the pathogenesis of human breast and ovarian cancer (9). Insulin-like growth factor-1 (IGF-1) receptor expression has been shown to be essential for maintenance of the transformed phenotype (10). Recently, "ret", another class of RTK, has been shown to be important in the pathogenesis of multiple endocrine neoplasia due to mutations in the catalytic domain which alter substrate specificity (11-13). Mutations in the fibroblast growth factor receptor family also cause human disease, such as achondroplasia (14). Thus, RTKs have been shown to be important in the pathogenesis of cancer and other diseases.

Recently, several approaches have been employed to isolate novel receptor tyrosine kinases. The most successful approach has been that based on using the polymerase chain reaction (PCR) and degenerate oligonucleotide primers corresponding to the conserved amino acid motifs within the kinase domain $(2,15)$. This has led to the isolation of several new tyrosine kinases of receptor and nonreceptor types. Adopting a similar strategy, two RTKs, EDDRl (16) and H-RYK, were identified from an epithelial ovarian cancer cell line, SKOV-3. This paper reports the isolation, expression, and biochemical characterization of H-RYK. During the course of this investigation, an identical human cDNA was published, and hence we have chosen to use the same name, H-RYK $(17,18)$. This represents a new class of receptor tyrosine kinases, with unusual sequence alterations in conserved motifs within the catalytic domain. The expression of H-RYK is localized to epithelial and stromal cells and is increased in malignant ovarian tumors. It codes for a 100-kD protein, which is expressed ubiquitously, but does not autophosphorylate in an in vitro kinase assay.

\section{MATERIALS AND METHODS}

\section{Isolation of cDNA Clones and Sequencing}

RTK 15 was isolated from the SKOV-3 cDNA library as previously described (16). All isolated cDNA clones were fully sequenced in both strands using a Sequenase kit (USB, Cleveland, $\mathrm{OH}$, U.S.A.) and the dideoxy chain termination method (19). Sequencing was performed using both oligonucleotide primers and M1 3 FSP/RSP primers on pBluescript SK. All oligonucleotide primers were synthesized on an Applied Biosystems $380 \mathrm{~A}$ synthesizer using standard chemistry.

\section{Northern Analysis}

A human multiple tissue Northern blot (Clontech Labs, Palo Alto, CA, U.S.A.) containing $2 \mu \mathrm{g}$ of poly(A) ${ }^{+}$RNA from eight different tissues was used. Hybridization was performed with the original RTK15 fragment as a probe and confirmed subsequently with the full-length cDNA. The probe was labeled using the random prime labeling technique with $\left[\alpha^{-32}\right]$ dCTP (Amersham, U.K.), and hybridization conditions were as described (16).

\section{In Situ Hybridization}

In situ hybridization was performed as described previously with some modifications $(16,20)$. The template for RTK15 was EcoRV linearized clone $15.5 \mathrm{BX} 3$ in pBluescript SK. The transcript was made with $T_{7}$ polymerase. As a control for the presence of RNA in all tissue compartments, sections from all blocks were hybridized with a $\beta$-actin probe (16).

\section{Polyclonal Antisera}

Peptides corresponding to residues $321-337$ and 551-568 (15.1 and 15.2) were chosen from the predicted amino acid sequence of H-RYK, based on hydrophilicity and antigenicity using the GCG program Peptide Structure. Peptides were synthesized and conjugated to thyroglobulin for immunization of rabbits as described previously (21). Polyclonal antisera were checked for specificity and titer by enzyme-linked immunosorbent assay against peptide, and the antibodies were purified using the Immunopure $\mathrm{Ag} / \mathrm{Ab}$ immobilization kit according to manufacturer's instructions (Pierce, U.K.). 


\section{Western Blotting}

$41 \mathrm{M}$ cells $\left(5 \times 10^{7}\right)$ were solubilized in lysis buffer (containing 1\% Triton X-100, $10 \mathrm{mM}$ sodium phosphate buffer [pH 7.0], $150 \mathrm{mM}$ Nacl, $250 \mathrm{mM}$ phenylmethylsulfonyl chloride, 70 $\mu \mathrm{g} / \mathrm{ml}$ aprotonin, $100 \mu \mathrm{M}$ sodium vanadate, 1 $\mu \mathrm{M}$ okadaic acid, $100 \mu \mathrm{M}$ bis [p-nitro-phenyl] phosphate, $2.5 \mu \mathrm{g} / \mathrm{ml}$ leupeptin, $2.5 \mu \mathrm{g} / \mathrm{ml}$ trypsin inhibitor, and $2.5 \mu \mathrm{g} / \mathrm{ml}$ pepstatin A) for 30 min at $4^{\circ} \mathrm{C}$. Lysates were centrifuged for $30 \mathrm{~min}$ at $13,000 \mathrm{rpm}$ at $4^{\circ} \mathrm{C}$. The supernatant was incubated with $1 \mu \mathrm{g}$ of purified antibody with or without $100 \mu \mathrm{g}$ of cognate peptide. Peptide and antibody were usually preincubated for $1 \mathrm{hr}$ at $4^{\circ} \mathrm{C}$ before adding to supernatant and protein- $\mathrm{A}$ sepharose beads for $2 \mathrm{hr}$ at $4^{\circ} \mathrm{C}$. Beads were centrifuged and washed twice with lysis buffer before being boiled $5 \mathrm{~min}$ in $40 \mu \mathrm{l}$ of $2 \times$ SDS/ PAGE sample buffer. SDS/PAGE $(6 \%)$ was performed as described (22).

Western blotting was performed using Amersham's ECL hybond filter overnight (12-18 hr) at $15 \mathrm{~V}$ in Tris-Glycine buffer. The filter was incubated with primary and secondary antibodies using the enhanced chemiluminescence kit according to manufacturer's instructions (Amersham). The primary antibody (15.1/15.2) was used at a concentration of $1 \mu \mathrm{g} / \mathrm{ml}$ and the secondary antibody (anti-rabbit polyclonal) at 1:5000 dilution. Autoradiographs were exposed from $1 \mathrm{~min}$ up to $1 \mathrm{hr}$ for optimal signal.

\section{Transfection}

The entire cDNA (15SC) was cloned into plasmid (pcDNAl) under the control of a CMV promoter. Chinese hamster ovary cells were grown to subconfluence in $90-\mathrm{mm}$ dishes using Dulbecco's Modified Eagle's medium (DMEM) supplemented with $10 \%$ fetal calf serum (FCS). The medium was aspirated from the dishes and 4.75 $\mathrm{ml}$ of DMEM was added together with the transfection cocktail (5-20 $\mu \mathrm{g}$ of cDNA in 5 $\mu \mathrm{l}$ of sterile distilled water, $40 \mu$ l phosphate-buffered saline (PBS), $200 \mu \mathrm{l}$ DEAE Dextran $(10 \mathrm{mg} / \mathrm{ml})$, $5 \mu \mathrm{l}$ chloroquine) and mixed by swirling. The cells were incubated for $2 \mathrm{hr}$; followed by washing once with PBS. Five milliliters of PBS plus $10 \%$ DMSO was added and the cells were incubated at room temperature for $1 \mathrm{~min}$. Subsequently, cells were washed twice with PBS and then cultured again in DMEM with $10 \%$ FCS at $37^{\circ} \mathrm{C}$ for $48 \mathrm{hr}$, before harvesting them with trypsin and EDTA for assaying for protein expression by Western blotting. Processing of the cells was performed as described above.

\section{Chromosomal Localization}

Metaphase spreads were examined from PHAstimulated normal human lymphocytes using standard cytogenetic techniques (23). The entire clone 15.5BX3 was used as a probe for fluorescent in situ hybridization (FISH) as described (24).

\section{Cell Lines}

Human cell lines were grown at $37^{\circ} \mathrm{C}$ in a humidified atmosphere of $5 \%$ carbon dioxide and maintained in DMEM and 10\% FCS with the following supplements: $10 \mathrm{mM}$ glutamine, 100 units/ml penicillin, and $12.5 \mu \mathrm{g} / \mathrm{ml}$ streptomycin. The ovarian cancer cell lines SKOV-3, PEOI, PEO4, PEO14, 4lM, 59M, OAW28, OAW42, and UC101 have been described previously (16). K562, HSB2, U937, Daudi, HL60, HeLa, C6, 293, BRL, and NIH3T3 were obtained from Cell Production Services at ICRF.

\section{RESULTS}

\section{Isolation of H-RYK cDNA Clones}

A short PCR fragment of 210 bp (RTK 15) was identified from a SKOV-3 cDNA library, using techniques described previously (16). Sequencing of this fragment showed a novel sequence unrelated to previous kinases. This was used as a probe, and two clones 15SC $(2.3 \mathrm{~kb})$ and 15P1 $(2.1 \mathrm{~kb})$ were identified. Sequencing of $15 \mathrm{SC}$ showed that it contained a continuous open reading frame. There was variation in the $3^{\prime}$ region due to the presence of longer untranslated sequences in 15P1. The clones were identical in sequence in the coding region except for an inframe 9-bp insertion in 15.5BX3 between nucleotides 868 and 876 resulting in the addition of three amino acids, ser-leu-gly. Comparison of our sequence with that of the earlier published sequence $(17,18)$ showed that they were identical except for some individual amino acid differences. The entire nucleotide and the putative amino acid sequence have been deposited with the EMBL database. 


\section{a. Conserved Protein Kinase Domains (I-IX)}

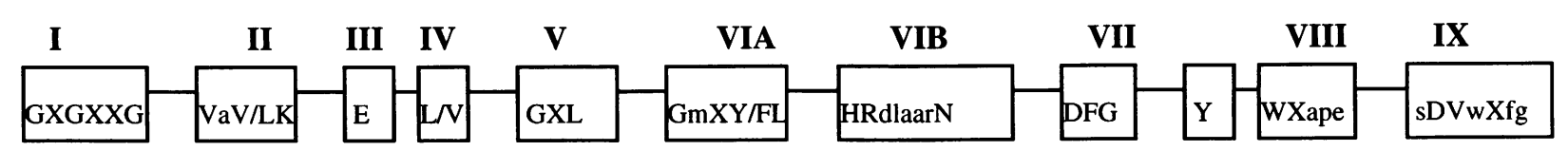

\section{b. H-RYK Protein Kinase Domains (I-IX)}

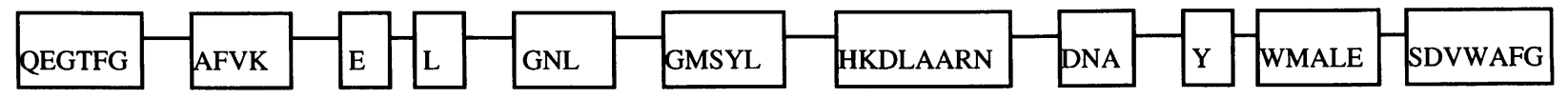

FIG. 1. Comparison of the catalytic domain of H-RYK with the conserved amino acids in the protein kinase family (2)

\section{Organization of H-RYK Protein}

The predicted amino acid sequence of the putative H-RYK protein has all the features suggestive of a transmembrane receptor. This includes an extracellular domain, transmembrane domain and a conserved catalytic domain. The N-terminal domain is novel and short compared with other kinases and has at least five glycosylation sites. There is also a stretch of four basic amino acid residues KRRK (amino acid 159-162) which probably represents a potential proteolytic cleavage site as found in the insulin receptor (25). The catalytic domain is about $39 \%$ identical to the $\mathrm{v}$-sea oncogene, but the rest of the protein is dissimilar (26). The carboxy-terminal region is only 19 amino acids long and short compared with other kinases. The critical changes in the catalytic domain compared with other kinases are shown in Fig. 1.

There are several tyrosine residues which are potential phosphorylation sites within the juxtamembrane and the catalytic domain. It is now possible to predict possible sites for binding to $\mathrm{SH}_{2}$ domain containing proteins based on the three amino acid sequences carboxy-terminal to the tyrosine $(13,27,28)$. There were four such binding sites identified within the catalytic domain which had good consensus sequences to bind to Grb-2, SHPTP2, Syk, and Vav $\mathrm{SH}_{2}$ proteins. The corresponding motifs within H-RYK are YMNW (tyrosine 386); YVDI and YHCL (tyrosine 516 and 468); YHCL (tyrosine 468); and
YMNW (tyrosine 386) respectively for each $\mathrm{SH}_{2}$ domain protein. Such motifs are usually found outside the catalytic domain in other RTKs.

\section{Chromosomal Localization of H-RYK}

The chromosomal localization of the H-RYK was determined by FISH analysis on normal human metaphase spreads using $15.5 \mathrm{BX} 3$ as a probe and was shown to map to $3 \mathrm{q} 22$ (Fig. 2). In contrast to the earlier report (17), no signals were identified on chromosome 17.

\section{Expression of H-RYK}

The clone $15 \mathrm{SC}$ was hybridized to poly $(\mathrm{A})^{+} \mathrm{RNA}$ from a panel of normal tissues and detected a single 3.0-kb transcript (Fig. 3). The gene was expressed in all tissues, but particularly strongly in skeletal muscle. To evaluate the significance of the 9-bp difference in the juxta-membrane domain between CDNA clones of H-RYK, reverse transcriptase PCR was performing using flanking primers. The two expected fragments were demonstrated in equal amounts from RNA of a panel of ovarian cell lines, and cDNA libraries (data not shown). The expression of H-RYK was also investigated by ribonuclease protection assay using a fragment from the $3^{\prime}$ untranslated region of $15.5 \mathrm{BX} 3$ as an antisense probe in a panel of eight ovarian cell lines. There was equivalent expression of message in 


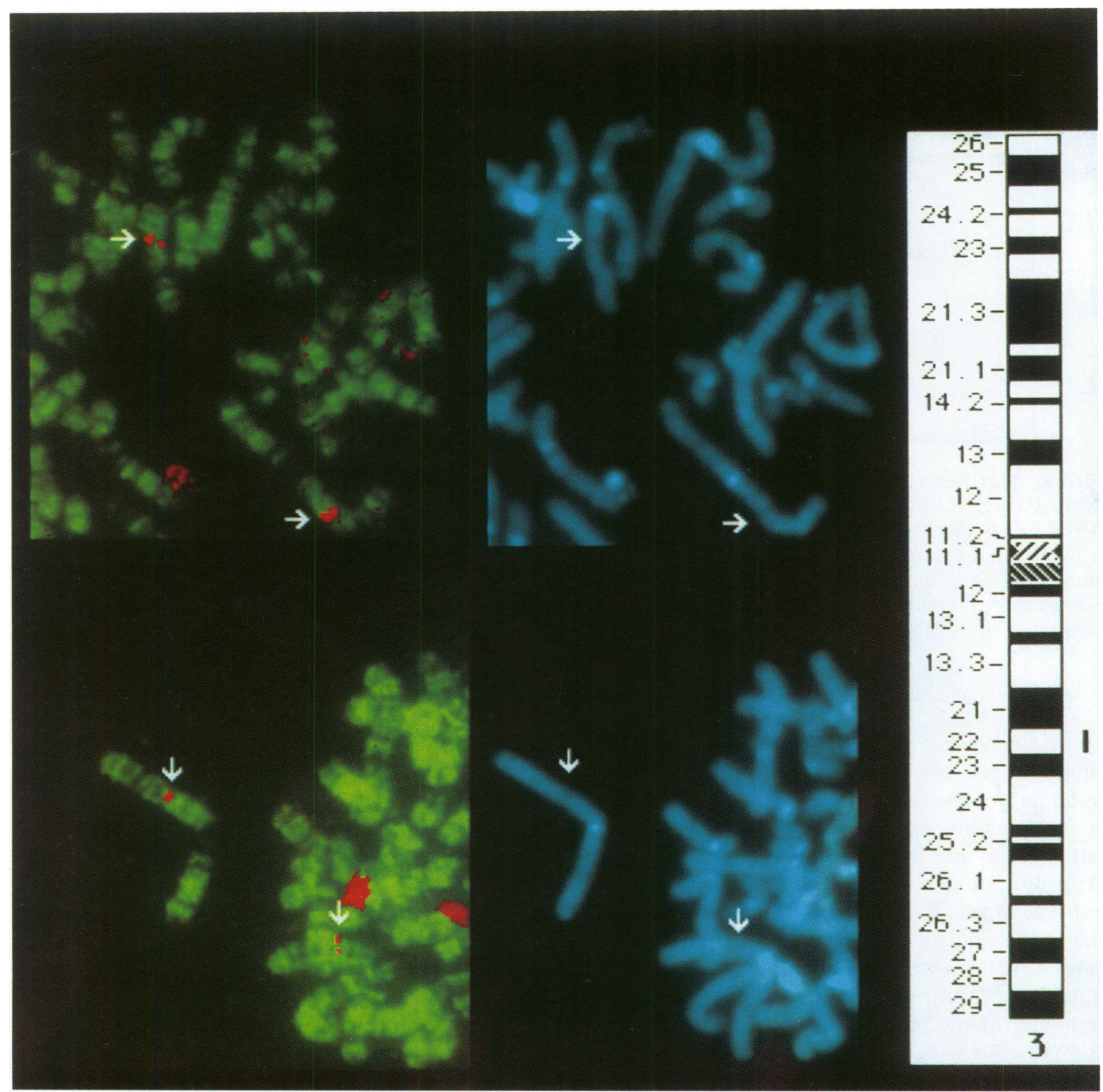

FIG. 2. Two partial metaphase spreads showing localization of probe to human chromosome $3 q 24$ (arrowed)

Signal was detected with Texas red on R-banded chromosomes stained with anti-bromodeoxyuridine-FITC. DAPI counterstaining of the same spreads produced a G-banding pattern. Metaphase spreads were processed using a Zeiss Axioscop microscope equipped with a CCD camera (Photometrics, Photometrics, AZ, U.S.A.). Separate images of probe signal, banding pattern, and counterstain were captured and colored. These images were then merged using a computer software developed by T. Rand and D. C. Ward (Yale University, New Haven, CT).

all the cell lines compared with a GAPDH control, without significant variation (data not shown).

\section{In Situ Hybridization to Normal Tissues} In order to assess the localization of H-RYK mRNA, in situ hybridization was performed on a panel of adult and fetal human tissues. In the colon, there was a low intensity of signal in the stroma (Fig. $4 \mathrm{a}$ and b). Surface epithelium also showed some expression. In the breast, the signal was primarily localized to mammary epithelium (Fig. 4c). In the lung (fetal) the mRNA signal was observed in the epithelium of devel- 


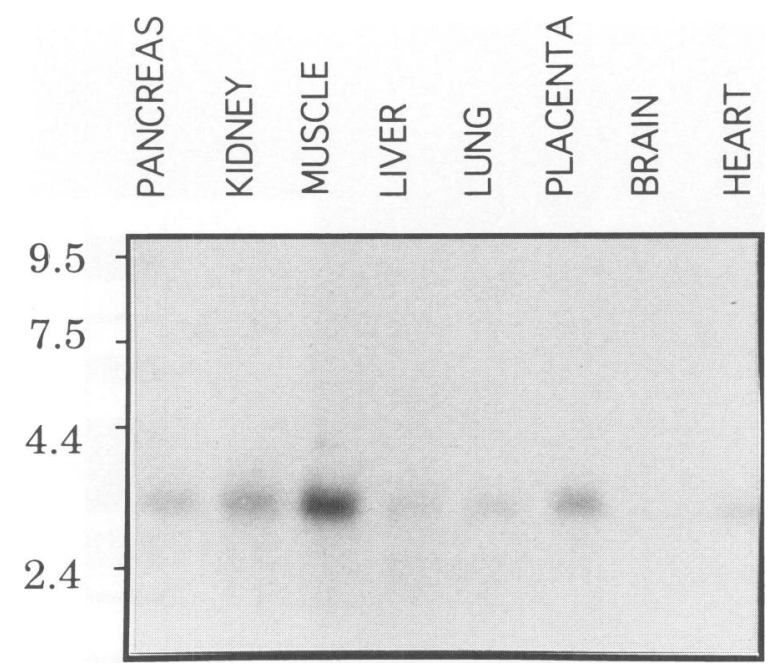

FIG. 3. Northern blot, $\operatorname{poly}(A)^{+}$RNA from adult tissues (Clonetech) hybridized to RTK15 PCR fragment

A single transcript of $3.0 \mathrm{~kb}$ was expressed. The autoradiogram was exposed for 5 days at $-70^{\circ} \mathrm{C}$. Size markers $(\mathrm{kb})$ are shown. Longer exposure showed a faint signal in brain.

oping alveoli. It was also present in lower intensity in the cuff of smooth muscles and epithelium of larger airways (Fig. 4d). H-RYK mRNA localized to the outer cortical layers of the fetal brain, with lesser amounts within the inner layers (Fig. 4e). In the fetal kidney, a high level of expression was observed in the neogenic zone of the cortex, but declined rapidly in the medulla (Fig. 4f). No definite signal was seen in the tubules. In the normal ovary, no expression was observed in the epithelium or stroma. Overall, H-RYK mRNA was localized to both the epithelial and mesenchymal compartments in the different tissues examined, in a pattern distinctive for each tissue.

\section{In Situ Hybridization of Ovarian Tumors}

In benign ovarian tumors, there was minimal amount of H-RYK mRNA, usually in the stroma (Fig. 5a). In borderline tumors of the ovary, the stromal expression was again more obvious than epithelial expression (Fig. 5b). In contrast, in malignant epithelial tumors, the mRNA levels were markedly increased compared to benign or borderline tumors (Fig. 5c). The localization of H-RYK mRNA was predominantly confined to the malignant epithelium, with some stromal signal evident in individual tumors. Adjacent normal epithelium expressed relatively low levels of mRNA. A panel of 25 malignant ovarian tumors of differing histology and grade were examined for H-RYK mRNA (Table 1). The data show that there is variation in levels, though $\mathrm{H}-\mathrm{RYK}$ is predominantly expressed in the malignant epithelial cells, with minimal to absent levels in the stroma.

\section{Biochemical Characterization}

In order to characterize the protein expressed by $\mathrm{H}-\mathrm{RYK}$, polyclonal antisera were raised in rabbits against synthetic peptides conjugated to thyroglobulin (15.1 and 15.2, corresponding to amino acid 321-337 and 552-568, respectively). The antisera were affinity purified against the cognate peptides. and used to identify the protein encoded by H-RYK by Western blotting in $41 \mathrm{M}$ cells, an ovarian cancer cell line. Two bands of equal intensity were identified migrating around $100 \mathrm{kD}$ by 15.1 and 15.2 , and blocked by cognate peptide (Fig. 6a). The two bands detected may represent two isoforms of H-RYK. Another protein of around $45 \mathrm{kD}$ was detected by the two antibodies on longer exposure (Fig. 6b). The HRYK cDNA was cloned into an expression vector pcDNAl and CHO cells were transiently transfected. An identical protein of $100 \mathrm{kD}$ was detected by the antisera in transfected cells, compared with the vector control transfected cells (Fig. 6c). Thus, H-RYK encodes for an approximately $100 \mathrm{kD}$ protein, and there maybe two isoforms, that maybe cleaved to form smaller proteins of $45 \mathrm{kD}$. To evaluate the catalytic activity of $\mathrm{H}-\mathrm{RYK}$, immune complex in vitro kinase assays were performed using 15.2 antiserum in $41 \mathrm{M}$ cells in the presence of ${ }^{32} \mathrm{P}$-ATP and $\mathrm{Mn}^{++}$. No evidence of autophosphorylation of H-RYK was detected in spite of varying experimental conditions, such as cations, addition of vanadate, or amount of cells, while positive control receptor tyrosine kinases (EDDR 1 and EGFR receptor) showed autophosphorylation. This data was confirmed by blotting with antiphosphotyrosine antibody following immunoprecipitation in the presence or absence of vanadate, using either antisera. No detectable phosphorylation was observed even upon transfection of H-RYK cDNA into $\mathrm{CHO}$ cells.

To analyze the expression of H-RYK further, a panel of cell lines (malignant and nonmalignant) from different tissues were examined using both antisera (Fig. 7). Ovarian cell lines 4lM, OAW28, UC101, PE06, and SKOV-3 expressed 

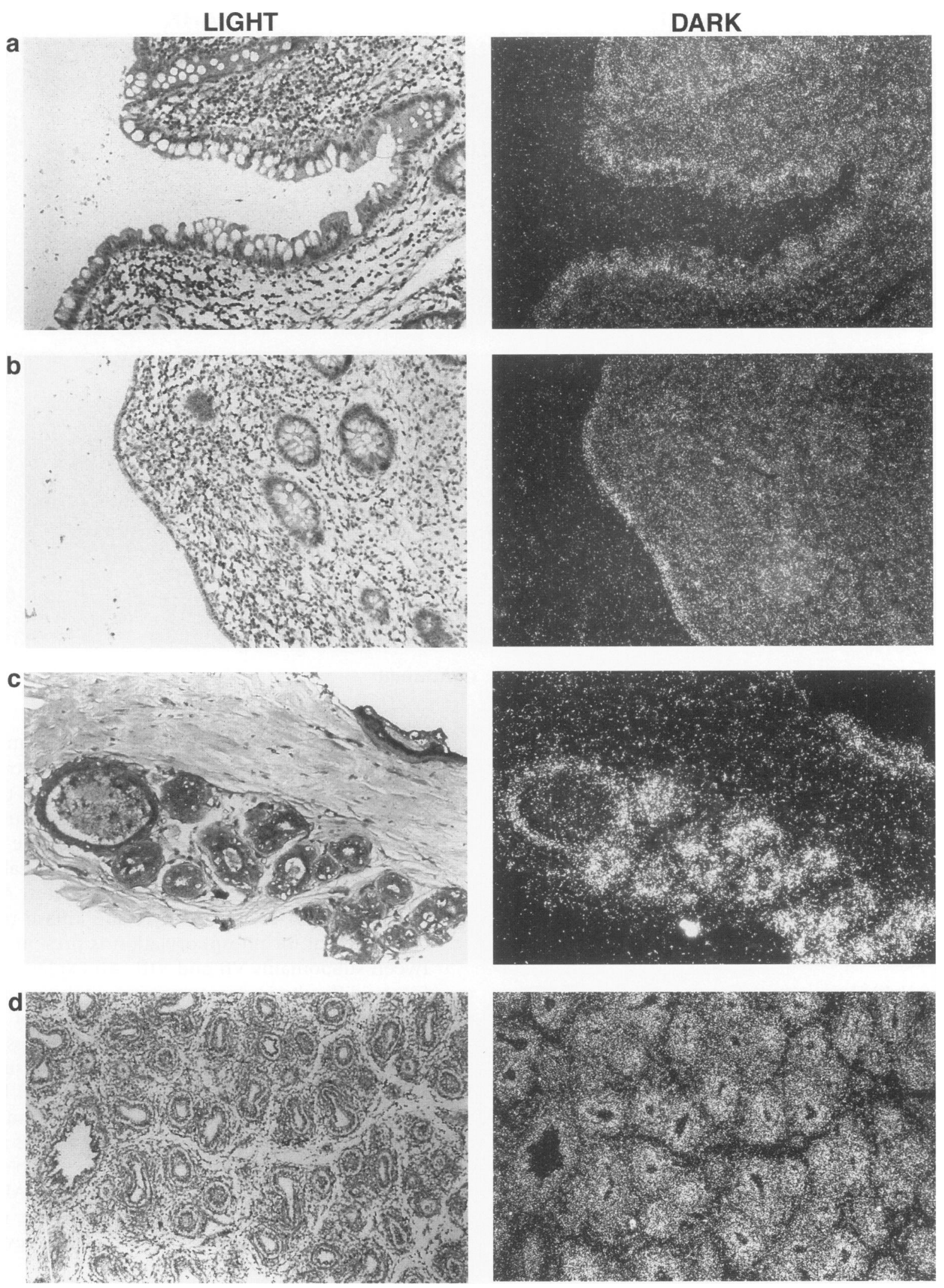

FIG. 4. In situ hybridization of a panel of human tissues using a ${ }^{35} \mathrm{~S}$-labeled antisense riboprobe (clone 15.5BX3)

Each pair of photograph shows both light and dark fields. (a and b) Colon. (c) Breast. (d) Fetal lung. (e) fetal brain. (f) fetal kidney. The dark fields show localization of message to the epithelial and stromal cells. Magnification before photography was between $10 \times$ and $20 \times$. 

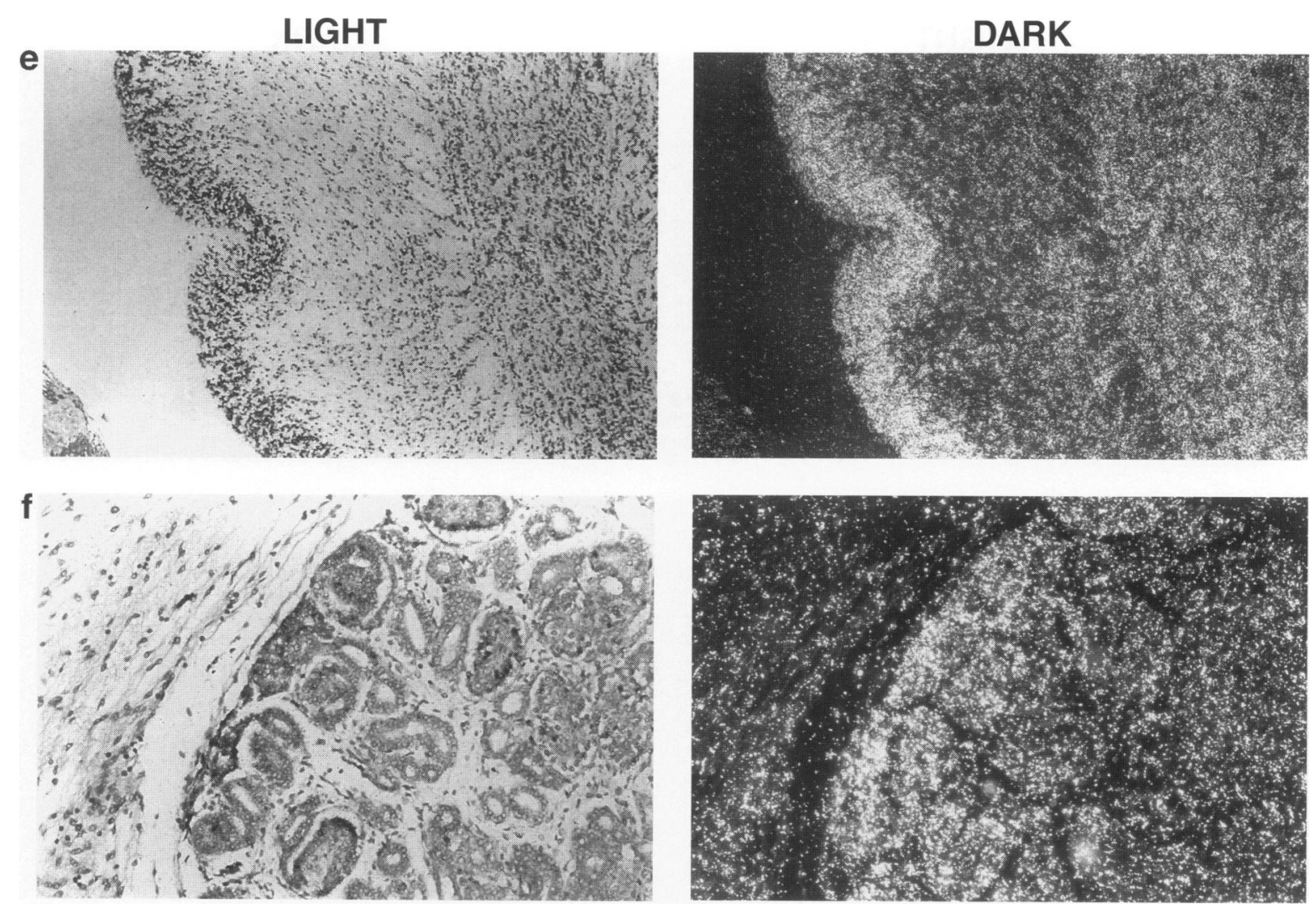

FIG. 4. Continued

the H-RYK protein. Daudi, HL60, K562 (hemopoietic cell lines) as well as 293 (fetal kidney), BRL (rat liver), C6 (rat glial tumour), and MDBK (bovine kidney) also expressed the H-RYK protein. Both 15.1 and 15.2 cross-reacted with the mouse RYK protein in NIH3T3 cells.

\section{DISCUSSION}

The H-RYK gene represents a new class of RTKs, due to the unique sequence alterations in the catalytic domain (Fig. 1) and the novel extracellular domain. The canonical motif GxGxxG in the subdomain I of the catalytic domain is altered to QxGxxG. This glycine rich loop is important in keeping apart the " $\mathrm{N}$ " and " $\mathrm{C}$ " terminal lobes of the catalytic domain by steric interactions with the "DFG" triplet in subdomain VII which is conserved among all kinases (29). In the latter motif in H-RYK, the critical aspartate is conserved but the phenylaline and glycine are altered to asparagine and alanine respectively giving the motif "DNA". The aspartate has been shown by in vitro mutagenesis to be important for kinase activity (30). Glycine to alanine is a conserved substitution, whereas phenylalanine to asparagine is a significant alteration. Structural analysis of the insulin receptor suggests that sequence alterations in these conserved residues may contribute to poor conformation of the activation loop (29). However, the lysine distal to the glycine rich loop which is implicated in ATP binding, is conserved. The tyrosine kinase residue essential for phosphorylation is present between subdomains VII and VIII. An explanation for the difficulty in demonstrating catalytic activity of the receptor may be because of one of the above sequence alterations. A receptor tyrosine kinase "klg" with an extracellular domain similar to the immunoglobulin superfamily and homology to v-sea $(39 \%)$ in the catalytic domain was recently isolated. This receptor also does not demonstrate any catalytic activity, in which the "DFG" triplet has been substituted by "ALS" (31). A detailed comparison of the kinase domains between " $k \lg ^{\prime}$ " and H-RYK failed to reveal any other significant differences.

Recently, it has been shown that peptide motifs surrounding the phosphorylated tyrosine provide unique sites for binding of $\mathrm{SH}_{2}$ domaincontaining proteins $(27,28)$. There are four po- 


\section{LIGHT}

2

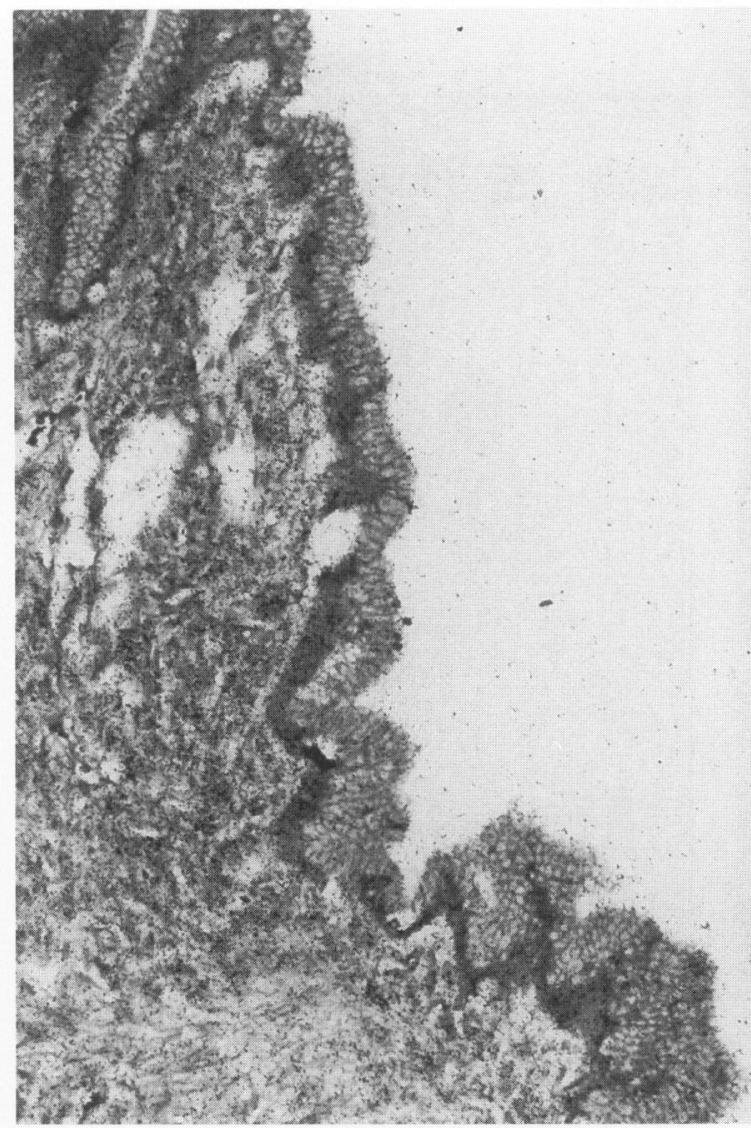

b

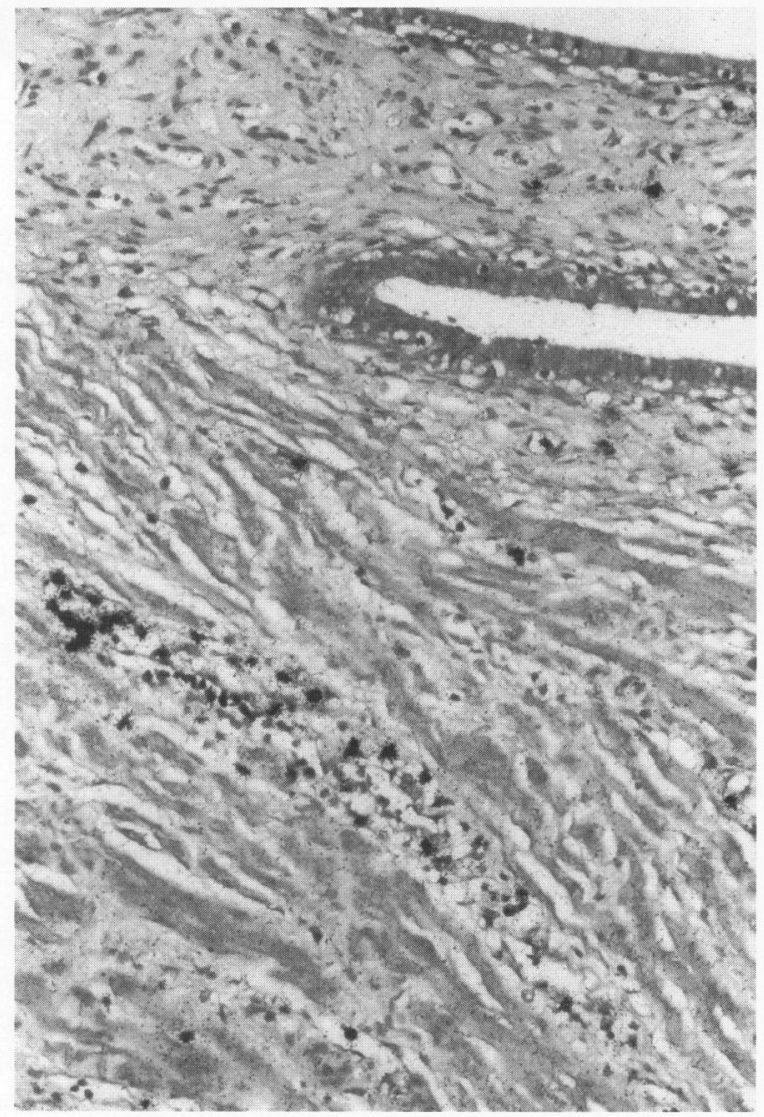

DARK
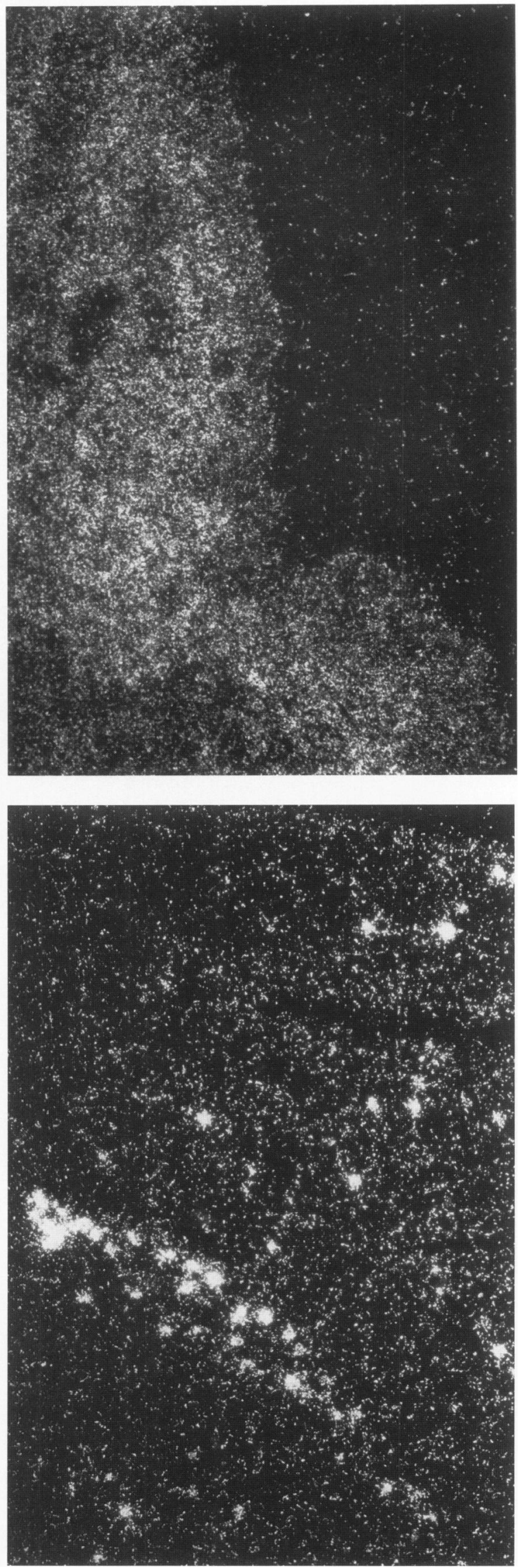

FIG. 5. In situ hybridization of a benign cystadenoma of the ovary (a), borderline tumor of the ovary (b) and well-differentiated serous adenocarcinoma of the ovary (c) 

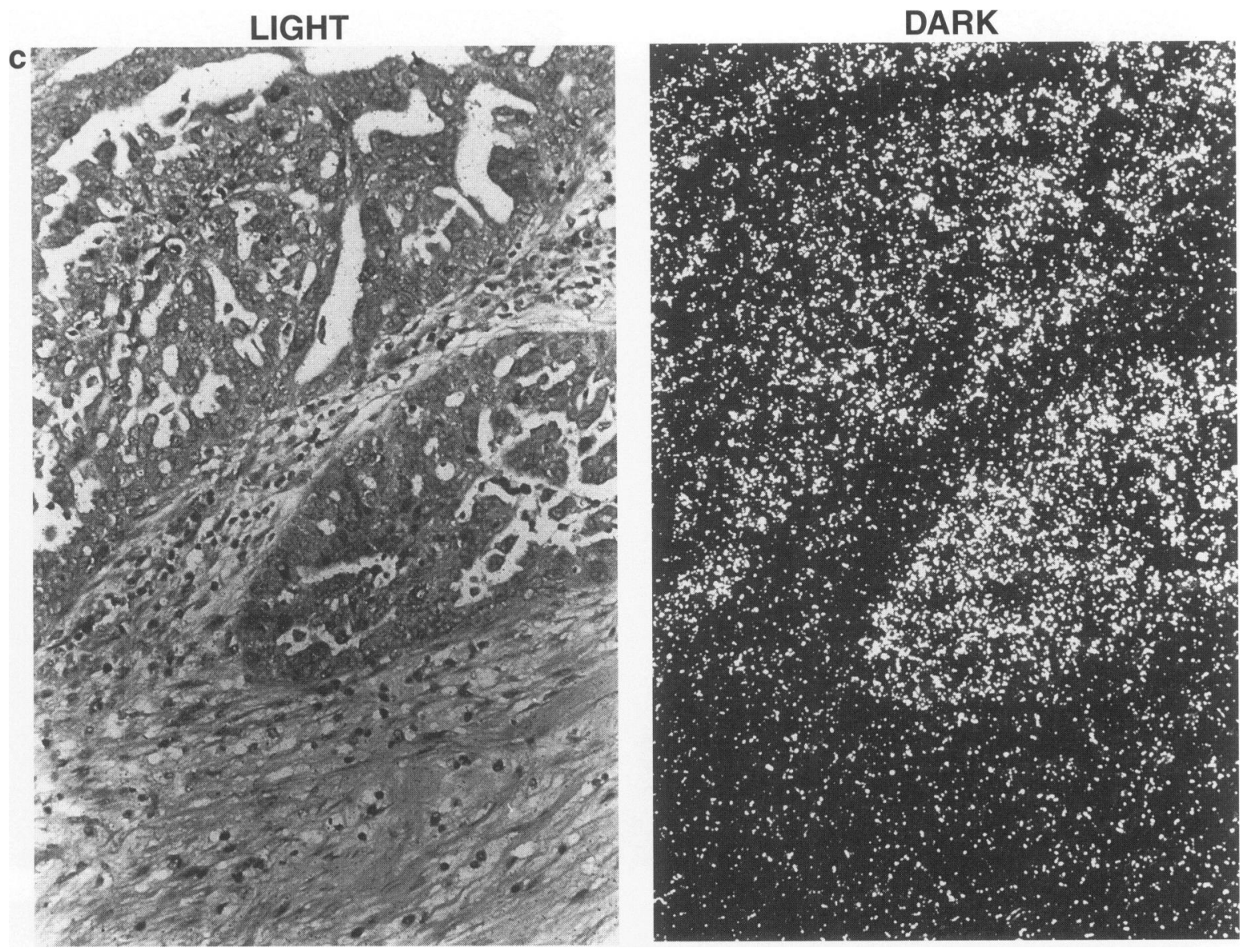

FIG. 5. Continued

tential tyrosine residues within the catalytic domain, with motifs suggestive of probable binding sites to known $\mathrm{SH}_{2}$ domain-containing proteins. Such motifs in other receptors usually occur outside the catalytic domain. This implies that the substrates for H-RYK maybe hitherto uncharacterized proteins or it may signal via an intermediate docking protein like IRS-1, as in the case of the insulin receptor (32). It is possible now to test directly the preferred substrate in vitro, by examining possible phosphorylation sites using techniques described by Songyang (27).

The mRNA for H-RYK is relatively abundant in skeletal muscle, though expressed in all other tissues. Unlike the mouse homolog of H-RYK $(33,34)$, only one transcript of $3.0 \mathrm{~kb}$ was observed. At the mRNA level, no significant variation was observed in eight ovarian cancer cell lines. The splice variant encoding an extra three amino acids, serine, leucine, and glycine, is immediately $\mathrm{NH}_{2}$ terminal to a tyrosine in the juxta-membrane domain. This variant was shown to be expressed equally at the mRNA level, in a panel of ovarian cell lines. There is as yet no evidence of residues amino terminal of the phosphotyrosine being important in $\mathrm{SH}_{2}$ domain interactions. The only exception to this rule, though yet to be demonstrated in vivo is the "NPXY" motif thought to be important in internalization of the LDL receptor, where amino-terminal residues may be critical $(35,36)$. Recently, it has been shown that the phosphotyrosine binding domain (PTB), in contrast to the $\mathrm{SH}_{2}$ binding domain of $\mathrm{SHC}$, binds to a phosphorylated tyrosine within the context of the "NPXY" motif. The asparagine is an important requirement for the binding of SHC (37). The two isoforms of H-RYK produced as a result of this splicing, may thus have different functions although this remains to be shown.

The expression of H-RYK in normal tissues as analyzed by in situ hybridization was unusual. In most of the tissues examined, the message was observed in epithelial cells and in the stroma. The expression in stroma, which comprises of various types of cells, suggests a role in cell-cell 
TABLE 1. Expression of H-RYK as determined by in situ hybridization on a panel of ovarian tumors

\begin{tabular}{|c|c|c|c|c|}
\hline \multirow[b]{2}{*}{ Name } & \multirow[b]{2}{*}{ Histological Type } & \multirow[b]{2}{*}{ Grade } & \multicolumn{2}{|c|}{ Expression $^{a}$} \\
\hline & & & Epithelium & Stroma \\
\hline S.R. ${ }^{b}$ & Mucinous adenocarcinoma & - & - & ++ \\
\hline U.K. ${ }^{b}$ & Mucinous adenocarcinoma & - & - & ++ \\
\hline J.T. ${ }^{b}$ & Serous adenocarcinoma & - & $+1-$ & $+1-$ \\
\hline J.G. ${ }^{b}$ & Mucinous adenocarcinoma & - & - & - \\
\hline B.A. ${ }^{b}$ & Mucinous adenocarcinoma & - & + & + \\
\hline A.L. & Endometroid adenocarcinoma & Well differentiated & - & - \\
\hline D.H. & Mucinous adenocarcinoma & Well differentiated & $+1-$ & + \\
\hline J.A. & Serous adenocarcinoma & Moderate diff. & $+1-$ & $+1-$ \\
\hline M.S. & Clear cell adenocarcinoma & Moderate diff. & + & - \\
\hline B.S. & Endometroid adenocarcinoma & Moderate diff. & +++ & + \\
\hline I.N.S. & Serous adenocarcinoma & Moderate diff. & +++ & + \\
\hline J.C. & Clear cell adenocarcinoma & Moderate diff. & $+1-$ & - \\
\hline S.B. & Mucinous adenocarcinoma & Moderate diff. & ++ & $+1++$ \\
\hline P.J. & Endometroid adenocarcinoma & $\begin{array}{l}\text { Moderate/focally } \\
\text { Poorly diff. }\end{array}$ & ++ & - \\
\hline M.B. & Endometroid adenocarcinoma & Poorly diff. & +++ & $+1-$ \\
\hline J.S. & Papillary adenocarcinoma & Poorly diff. & ++ & - \\
\hline E.M. & Endometroid adenocarcinoma & Poorly diff. & ++ & $+1-$ \\
\hline E.K. & Clear cell adenocarcinoma & Poorly diff. & $+1-$ & - \\
\hline J.N. & Endometroid adenocarcinoma & Poorly diff. & nd & nd \\
\hline G.C. & Serous adenocarcinoma & Poorly diff. & +++ & - \\
\hline B.J. & Clear cell adenocarcinoma & Poorly diff. & ++ & \\
\hline C.B. & Clear cell adenocarcinoma & Poorly diff. & - & - \\
\hline M.C. & Mucinous adenocarcinoma & Poorly diff. & + & - \\
\hline B.S. & Serous adenocarcinoma & Poorly diff. & +++ & - \\
\hline J.L. & Serous adenocarcinoma & Poorly diff. & + & $=$ \\
\hline J.R. & Serous adenocarcinoma & Poorly diff. & +++ & - \\
\hline P.S. & Serous adenocarcinoma & Poorly diff. & $+1-$ & - \\
\hline M.A. & Serous adenocarcinoma & Poorly diff. & + & - \\
\hline P.R. & Serous adenocarcinoma & Poorly diff. & ++ & - \\
\hline
\end{tabular}

interactions. This is suggested further by the presence of leucine rich motifs in the extracellular domain of H-RYK, observed in other cell adhesion molecules.

The pattern of expression in the ovary is interesting. In the normal adult ovary, there was little expression in the normal ovarian epithelium or stroma. In benign and borderline tumors, increased signal strength from the mRNA in the stroma was observed with minimal epithelial expression. In contrast, in malignant epithelial tumors, there was a pronounced increase in expression predominantly localized to the epithelium. Adjacent normal epithelium tissue in sections of malignant ovarian tumors did not show any expression of H-RYK. The explanation for 


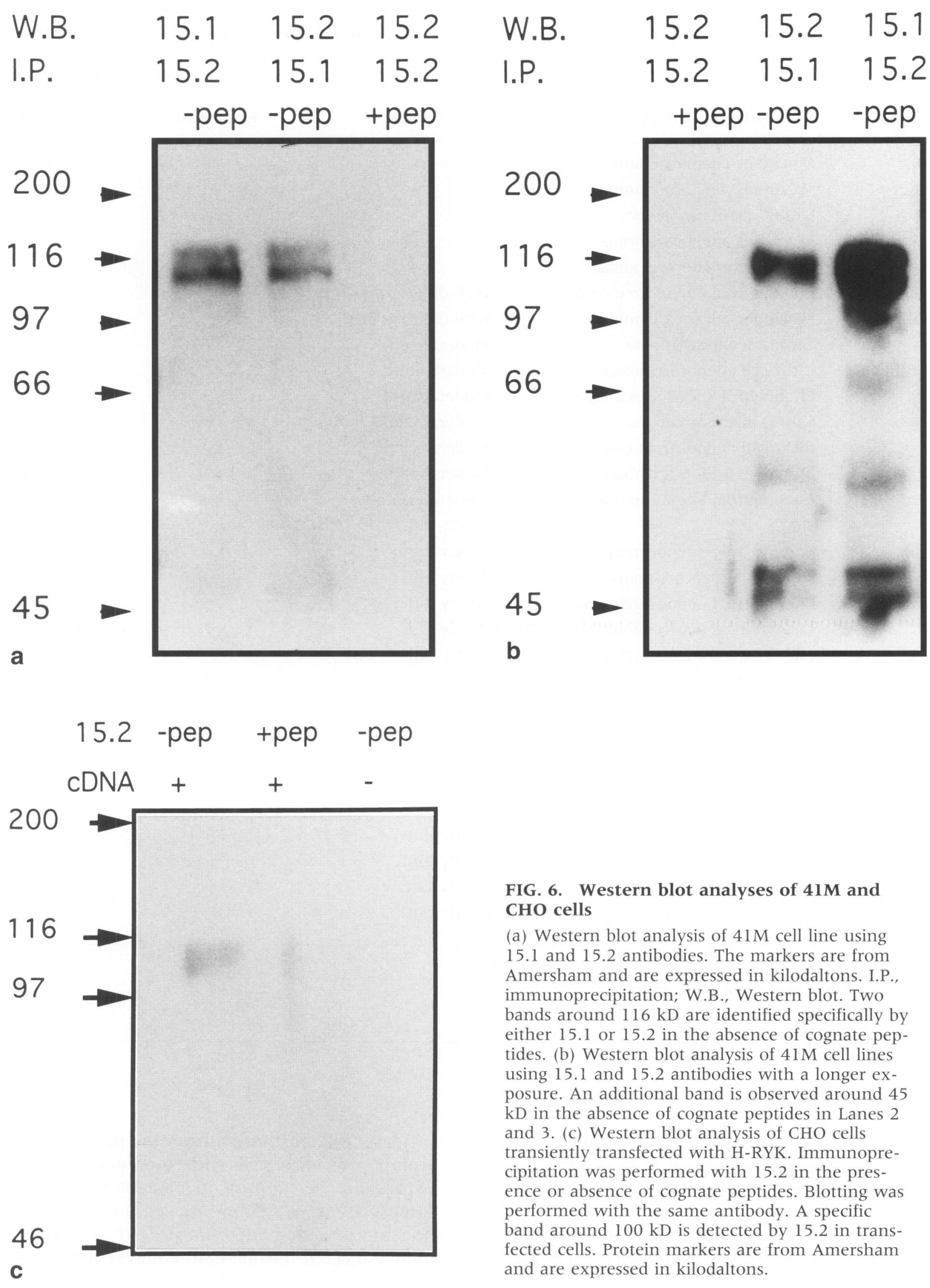




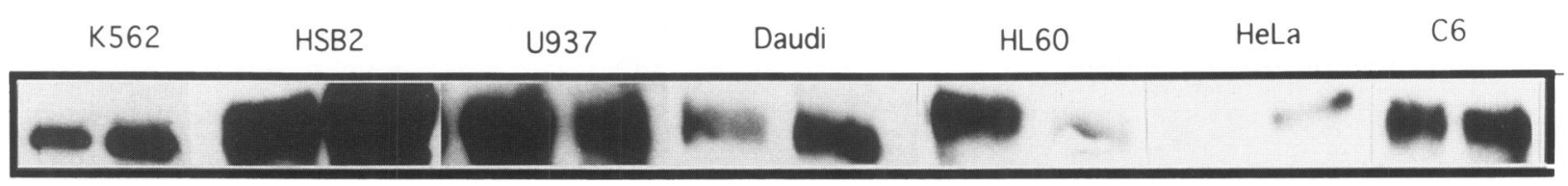

FIG. 7. A composite photograph of Western blot analysis of cell lines derived from different tissues

The antibody 15.1/15.2 was used in immunoprecipitation and Western blotting. A protein of $\approx 100 \mathrm{kD}$ was identified in all cell lines examined.

such differential pattern of expression in benign over malignant tumors is at present unclear. Detailed analysis of a panel of malignant ovarian tumors confirmed this observation. Further evaluation of the expression of H-RYK using antibodies will have to be performed to confirm if the levels of H-RYK mRNA result in similar patterns of expression of the protein.

The proteins immunoprecipitated by antisera specific to H-RYK was found to be approximately $100 \mathrm{kD}$. There were two bands of equal intensity identified in $41 \mathrm{M}$ cells, one slightly larger than $116 \mathrm{kD}$ and the smaller one less, suggesting the presence of two isoforms. Careful examination of the gel, revealed another band at approximately $46 \mathrm{kD}$. This may represent a protein product cleaved from the extracellular domain at the "KRRK" sequence. Alternatively, it may signify an associated protein which is co-immunoprecipitated. The size of the $100-\mathrm{kD}$ protein is larger than that predicted from the cDNA by at least $30-40 \mathrm{kD}$. It is possible that this is due to glycosylation, as there are at least five potential $\mathrm{N}$-glycoprotein sites in the extracellular domain of H-RYK. In intact $41 \mathrm{M}$ cells, no change in mobility was observed following tunicamycin treatment for at least $24 \mathrm{hr}$, which maybe reflective of the half-life of H-RYK, other than absence of glycosylation. The H-RYK protein is expressed ubiquitously as shown by the results of a screen on a panel of malignant and non-malignant cell lines from different tissues.

Although H-RYK on primary structure has a high degree of homology to RTKs, no catalytic activity could be demonstrated. This maybe due to low basal levels of phosphorylation in the absence of its ligand. Alternatively, the critical changes in the sequence maybe a contributing factor by altering tertiary structure. To investigate the latter, an approach based on construction of a chimeric receptor would be valuable. This has also been informative in assessing the function of the c-erbB3 protein, a member of the epidermal growth factor receptor (EGFR) family, where it was difficult to demonstrate catalytic activity. Substitution of the extracellular domain of c-erbB3 with that of EGFR showed that the catalytic domain of c-erbB 3 was functional when stimulated with EGF (38). However, NIH3T3 cells contain some murine EGF receptors which might have been contributory to the phosphorylation observed in the chimaeric receptor transfectants. More recently it has been shown that heregulin stimulates phosphorylation of c-erbB 3 by heterodimerisation with cerbB2 (39). An approach based on chimaeric receptors will demonstrate whether the catalytic domain of H-RYK can phosphorylate substrates when stimulated with an appropriate ligand. If the catalytic activity cannot be demonstrated, then the putative physiological function of such a receptor and its ligand is intriguing. One possibility as discussed for the " $\mathrm{klg}$ " receptor is that of signal attenuation by formation of inactive dimers with other RTKs (31). The increase in expression in malignant ovarian tumors, in such a context, has to be explored further to understand the role of such a receptor in its pathogenesis. The recently isolated Drosophila derailed $(d r l)$ gene has been shown to be homologous to the H-RYK gene in the catalytic domain $(50 \%)$. This gene is functionally important for selection of neuronal pathways $(40)$. It is possible that H-RYK might well have similar functions in mammalian systems.

\section{ACKNOWLEDGMENTS}

We are grateful to Dr. J. Trowsdale and Dr. S. Chatterjee for the SKOV-3 and normal ovary cDNA libraries. Drs. A. P. Wilson and S. Langdon are gratefully acknowledged for the cell lines. ICRF Cell Production Services, In Situ Hybridization Service and Peptides Synthesis Laboratories are acknowledged. This work was supported by 
the Imperial Cancer Research Fund. Mr. R. Katso is a Rosina Valerie Howell Fellow.

\section{REFERENCES}

1. Hunter T. (1987) A thousand and one protein kinases. Cell 50: 823-829.

2. Hanks SK, Quinn AM, Hunter T. (1988) The protein kinase family: Conserved features and deduced phylogeny of the catalytic domains. Science 241: 42-52.

3. Schlessinger J, Ullrich A. (1992) Growth factor signalling by receptor tyrosine kinases. Neuron 9: 383-391.

4. Pawson T. (1995) Protein modules and signalling networks. Nature 373: 573-579.

5. Pawson T. (1995) Getting down to specifics. Nature 373: 477-478.

6. Darnell Jr JE, Kerr IM, Stark GR. (1994) Jak-STAT pathways and transcriptional activation in response to IFNS and other extracellular signalling proteins. Science 264: 1415-1421.

7. Heldin C-H. (1995) Dimerization of cell surface receptors in signal transduction. Cell 80: 213-223.

8. Cantley LC, Auger KR, Carpenter C, et al. (1991) Oncogenes and signal transduction. Cell 64: 281-302.

9. Slamon DJ, Godolphin W, Jones LA, et al. (1989) Studies of the HER-2/neu proto-oncogene in human breast and ovarian cancer. Science 244: 707-712.

10. Baserga R. (1995) The insulin-like growth factor I receptor: A key to tumor growth? Cancer Res. 55: 249-252.

11. Eng C, Smith DP, Mulligan LM, et al. (1994) Point mutation within the tyrosine kinase domain of the RET proto-oncogene in multiple endocrine neoplasia type $2 \mathrm{~B}$ and related sporadic tumours. Hum. Mol. Genet. 3: 237-241.

12. Mulligan LM, Kwok JBJ, Healey CS, et al. (1993) Germ-line mutations of the RET proto-oncogene in multiple endocrine neoplasia type 2A. Nature 363: 458-460.

13. Songyang Z, Carraway KL, Eck MJ, et al. (1995) Catalytic specificity of protein tyrosine kinases is critical for selective signalling. Nature 373: 536-539.

14. Shaing R, Thompson LM, Zhu Y-Z. (1994) Mutations in the transmembrane domain of FGFR3 cause the most common genetic form of dwarfism, achondroplasia. Cell 78: 335342.

15. Wilks AF. (1989) Two putative protein-tyrosine kinases identified by application of the polymerase chain reaction. Proc. Natl. Acad. Sci. U.S.A. 86: 1603-1607.

16. Laval S, Butler R, Shelling AN, Hanby AM, Poulsom R, Ganesan TS. (1994) Isolation and characterisation of an epithelial specific receptor kinase from an ovarian cancer cell line. Cell Growth Differ. 5: 1173-1183.

17. Stacker SA, Hovens CM, Vitali A, et al. (1993) Molecular cloning and chromosomal localisation of the human homologue of a receptor related to tyrosine kinases. Oncogene 8: 1347-1356.

18. Tamagnone L, Partanen J, Armstrong E, et al. (1993) The human RYK cDNA sequence predicts a protein containing two putative transmembrane segments and a tyrosine kinase catalytic domain. Oncogene 8: 20092014.

19. Sanger F, Nicklen S, Coulson R. (1977) DNA sequencing with chain-terminating inhibitors. Proc. Natl. Acad. Sci. U.S.A. 74: 54635467.

20. Senior PV, Critchley DR, Beck F, Walker RA, Varley JM. (1988) The localisation of laminin mRNA and protein in the postimplantation embryo and placenta of mouse: An in situ and immunocytochemical study. Development 104: 431-446.

21. Walker LC, Ganesan TS, Dhut S, et al. (1987) Novel chimaeric protein expressed in Philadelphia positive acute lymphoblastic leukaemia. Nature 329: 851-853.

22. Laemmli UK. (1970) Cleavage of structural proteins during the assembly of the head bacteriophage T4. Nature 227: 680-685.

23. Rooney DE, Czepulkowski BH (eds). (1986) Human Genetics: A Practical Approach. IRL Press, London.

24. Shelling AN, Butler R, Jones T, Laval S, Boyle JM, Ganesan TS. (1995) Localisation of an epithelial-specific receptor kinase (EDDR1) to chromosome 6q16. Genomics 25: 584-587.

25. Ullrich A, Bell JR, Chen EY, et al. (1985) Human insulin receptor and its relationship to the tyrosine kinase family of oncogenes. Nature 313: 756-761.

26. Smith D, Vogt PK, Hayman MJ. (1989) The $v$-sea oncogene of avian erythroblastosis virus S13-Another member of the protein 
tyrosine kinase gene family. Proc. Natl. Acad. Sci. U.S.A. 86: 5291-5295.

27. Songyang Z, Shoelson SE, Chaudhuri M, et al. (1993) SH2 domains recognize specific phosphopeptide sequences. Cell 72: 767-778.

28. Songyang Z, Shoelson SE, McGlade J, et al. (1994) Specific motifs recognized by the $\mathrm{SH} 2$ domains of Csk, 3BP2, fps/fes, GRB-2, HCP, SHC, Syk, and Vav. Mol. Cell. Biol. 14: 27772785.

29. Hubbard SR, Wei L, Ellis L, Hendrickson WA. (1994) Crystal structure of the tyrosine kinase domain of the human insulin receptor. Nature 372: 746-753.

30. Moran MF, Kock CA, Sadowski I, Pawson T. (1988) Mutational analysis of a phosphotransfer motif essential for $\mathrm{v}$-fps tyrosine kinase activity. Oncogene 3: 665-672.

31. Chou Y-H, Hayman MJ. (1991) Characterisation of a member of the immunoglobulin gene superfamily that possibly represents an additional class of growth factor receptor. Proc. Natl. Acad. Sci. U.S.A. 88: 4897-4901.

32. White MF. (1994) The IRS-1 signaling system. Curr. Opin. Genet. Dev. 4: 47-54.

33. Hovens CM, Stacker SA, Andres A-C, Harpur AG, Ziemiecki A, Wilks AF. (1992) RYK, a receptor tyrosine kinase-related molecule with unusual kinase domain motifs. Proc. Natl. Acad. Sci. U.S.A. 89: 11818-11822.

34. Kelman Z, Simon-Chazottes D, Guenet J-L, Yarden Y. (1993) The murine vik gene (chro-

Contributed by D. Weatherall on November 21, 1995. mosome 9) encodes a putative receptor with unique protein kinase motifs. Oncogene 8: 37-44.

35. Bansal A, Gierasch LM. (1991) The NPXY internalization signal of the LDL receptor adopts a reverse-turn conformation. Cell 67: 1195-1201.

36. Chen W-J, Goldstein J, Brown MS. (1990) NPXY, a sequence often found in cytoplasmic tails, is required for coated pit-mediated internalization of the low density lipoprotein receptor. J. Biol. Chem. 265: 3116-3123.

37. Kavanaugh WM, Turck CW, Williams LT. (1995) PTB domain binding to signaling proteins through a sequence motif containing phosphotyrosine. Science 268: 1177-1179.

38. Prigent SA, Gullick WJ. (1994) Identification of c-erbB-3 binding sites for phosphatidylinositol 3'kinase and SHC using an EGF receptor/c-erbB-3 chimera. EMBO J. 13: 28312841.

39. Wallasch C, Weib FU, Niederfellner F, Jallal B, Issing W, Ullrich A. (1995) Heregulindependent regulation of HER2/neu oncogenic signaling by heterodimerization with HER3. EMBO J. 14: 4267-4275.

40. Callahan CA, Muralidhar MG, Lundgren SE, Scully AL, Thomas JB. (1995) Control of neuronal pathway selection by a Drosophila receptor protein-tyrosine kinase family member. Nature 376: 171-174. 